\title{
VIAJEROS DEL SIGLO XIX: EL LINAJE MEXICANO Y LAS 11 MIL LEGUAS DE FRANCISCO BULNES POR EL HEMISFERIO NORTE
}

Daniar Chávez Jiménez*

RESUMEN: El siguiente escrito indaga la obra Sobre el Hemisferio norte. Once mil leguas, de Francisco Bulnes, con la intención de retomar el estudio y el análisis de los viajeros mexicanos del siglo XIX. Destaca el estudio de la alteridad cultural y el conocimiento del otro desde el marco de los estudios etnográficos. También indaga cómo se forjó la representación del otro bajo los parámetros del progreso, propios del proceso civilizatorio llevado a cabo por Occidente durante el siglo XIX.

$$
\text { sose }
$$

ABSTRACT: In this article, we will analyze Francisco Bulnes' Eleven Thousand Leagues Across The Northern Hemisphere in order to reanalyze the nineteenth century Mexican travelers. We will highlight the importance of cultural alterity and the knowledge of the other from the standpoint of the significant ethnographic studies. We will also investigate the way how the perspective of the other was molded according to the parameters of progress from the civilizing process in the West during the nineteenth century.

PALABRAS CLAVE: Relato de viaje, siglo XIX, viajeros mexicanos, literatura mexicana. KEY WORDS: a journey's tale, nineteenth century, Mexican travelers, Mexican literature.

RECEPCIÓN: 6 de agosto de 2013.

APROBACIÓN: 12 de septiembre de 2013.

* Departamento de Filología "Dr. Luis Mario Schneider", Facultad de Humanidades, Universidad Autónoma del Estado de México. 
CITAM Derechos Reservados.

La reproducción total o parcial de este artículo se podrá hacer si el ITAM otorga la autorización previamente por escrito. 


\section{VIAJEROS DEL SIGLO XIX: EL LINAJE MEXICANO Y LAS 11 MIL LEGUAS DE FRANCISCO BULNES POR EL HEMISFERIO NORTE*}

Viajar es arriesgar la integridad pero también apostar el alma, sobre todo para quien está dispuesto a dejar testimonio escrito de su vocación. El viaje es iniciación y ritual de paso; su consecuencia

final es la transformación, y los beneficiados somos, finalmente, los lectores, que también viajamos gracias a la imaginación. Mejor ser viajeros imprudentes que prudentes sedentarios, escribió

John Kyats. Vale evocarlo porque el siglo XIX [...] es el gran siglo romántico, ese que postula el viaje como aventura del alma, exploración de los sentidos, traza del mapa invisible que la ciudad ofrece, tanto a sus nativos como los que se transforman en sus nuevos descubridores.

Vicente Quirarte, Republicanos en otro imperio.

Viajero mexicano a $N Y$

El paso de Venus entre la Tierra y el Sol se verifica todos los años, pero solamente en los intervalos de 100 años a 8 y de 8 a 122 años es cuando pasa por el disco del Sol, pues en los demás pasos el planeta se proyecta fuera de la masa solar. Así pues el futuro paso tendrá lugar en 1882 y después hasta el año 2004. Se aprovecha esta observación para medir la distancia del Sol a la Tierra.

Francisco Bulnes, Sobre el hemisferio norte.

Once mil leguas

\section{La estirpe del viajero}

En las últimas décadas, los libros de viajeros mexicanos del siglo XIX hacia el extranjero han recibido una atención cada vez mayor dentro de los estudios culturales y literarios de nuestros espacios académicos. Prueba de ello es la constante reedición de este tipo de relatos que permanecían olvidados en los anaqueles del fondo reservado de la Biblioteca Nacional, hasta que distintas co-

* El presente artículo es producto del proyecto de investigación CONACYT: CVU 39767. 
lecciones de diversas editoriales iniciaron el trabajo de recuperación de estos textos que se creían perdidos o que sólo aparecían en las bibliotecas y las librerías públicas, parcialmente reeditados. Menciono aquí, a manera de ejemplo, algunas de las ediciones recientemente preparadas por la colección Al siglo XIX. Ida y regreso de la UNAM, como la de Rosa María Talavera sobre el libro de Ignacio Martínez, Recuerdos de un viaje en América, Europa y África (1884), en el 2009; la realizada por Manuel Sol a la obra de Justo Sierra O’Reilly, Impresiones de un viaje a los Estados Unidos de América y al Canadá (1851), editada en el 2012 y, hacia finales también del 2012, la aparición de la edición preparada por José Ricardo Chaves al libro de Francisco Bulnes, Sobre el hemisferio norte. Once mil leguas (1875), objeto de este estudio. ${ }^{1}$

¿Pero por qué hablar de relatos perdidos dentro del recuerdo de la conciencia nacional? ¿Y más aún, por qué reeditar esos textos que fueron paulatinamente olvidados por académicos y lectores en general? La respuesta es sencilla: porque los libros de viajes tienen una dimensión testimonial que manifiesta intereses, inquietudes y preocupaciones del escritor/viajero, dimensión que, como explica Luis Alburquerque, se da en una trayectoria bidireccional, es decir, atiende las noticias y las novedades de las culturas visitadas, pero también representa una muestra del bagaje cultural del visitante y de la sociedad que representa. ${ }^{2}$

Las razones atienden, además, a un asunto de interés tanto cultural como social, no por nada se ha considerado a los escritores/viajeros como los primeros etnógrafos. ${ }^{3} \mathrm{Y}$, en efecto, fue el viajero, por lo menos hasta

${ }^{1}$ La edición de José Ricardo Chaves sobre el texto de Francisco Bulnes es facsimilar, por lo que aquí se actualiza la ortografía y la puntuación de las citas del texto. Para la cita de la obra utilizo la siguiente abreviatura: SHN (Francisco Bulnes, Sobre el hemisferio norte, once mil leguas. Impresiones de viaje a Cuba, los Estados Unidos, el Japón, China, Conchinchina, Egipto y Europa, 2012, México, UNAM, Coordinación de Humanidades, estudio preliminar de José Ricardo Chaves.

${ }^{2}$ Luis Alburquerque García, "Los libros de viajes como género literario”, en Manuel Lucena Giraldo y Juan Pimentel (coords.), Diez estudios sobre literatura de viajes, 2006, Madrid, Consejo Superior de Investigación Científica, Instituto de la Lengua Española, p. 81.

${ }^{3}$ Ver José Manuel Herrero Massari, Libros de viajes de los siglos XVI y XVII en España y Portugal: lecturas y lectores, 1999, Madrid, Fundación Universitaria Española; Mary Louise Pratt, Ojos imperiales. Literatura de viajes y transculturación, 2005, Buenos Aires, Fondo de Cultura Económica; Jean Richard, Les récites de voyages et de pèlerinages, 1981, Brèpols, Turnhout. 
el arribo de la antropología científica que entró en auge a partir de la segunda mitad del siglo XIX, quien proporcionó los primeros indicios y constituyó las técnicas para obtener información de otras culturas que, finalmente, dieron como resultado la descripción y la representación de los pueblos visitados. ${ }^{4}$

Hasta aquí, la dirección que toma el estudio de la narrativa de viaje se entiende por sí misma, pero en el caso mexicano hay que precisar otras particularidades que, como explicó Ignacio Manuel Altamirano en su introducción al libro de Luis Malanco, Viaje a oriente (1882-1883), crearon a lo largo de los siglos a un hombre nacional de un carácter fuertemente sedentario. Es preciso aclarar, como ya lo ha señalado Vicente Quirarte siguiendo a Altamirano, que las prohibiciones durante la dominación española impusieron severas restricciones, que no sólo arrebataron a los antiguos pobladores de Anáhuac la libertad, ${ }^{5}$ sino también ciñeron los impulsos naturales del hombre por recorrer y andar su propia tierra.

Esto dio como resultado, como afirma Altamirano, que la literatura de viajes en nuestro país fuera escasa (si bien hay notables excepciones), no sólo en lo relativo a los viajeros que recorrieron el territorio nacional, sino también en quienes se aventuraron a recorrer otras latitudes y otros continentes. ${ }^{6}$ No obstante, cabe señalar que el inventario de viajeros mexicanos hacia el extranjero se incrementaría durante el siglo XIX (si la comparamos con los viajeros mexicanos de las épocas posteriores al "descubrimiento" y la colonia), aunque la gran cantidad de bibliografía que existe sobre viajeros europeos y norteame-

${ }^{4}$ Ver Marco Urdapilleta, La representación de la alteridad cultural y su función en la narrativa de viaje. Estudio de dos casos: El relato de viaje a indias del siglo XVI y la novela de viaje (proyecto de investigación), 2013, México, Facultad de Humanidades, UEAM (documento sin publicar); Patricia Almarcegui, "El otro y su desplazamiento en la última literatura de viaje”, en Revista de Literatura, 2011, vol. 73., núm. 145, pp. 283-90; Bárbara Fick, El libro de viajes en la España medieval, 1998, Santiago de Chile, Editorial Universidad; Federico Guzmán Rubio, "Tipología del relato de viajes en la literatura hispanoamericana: definiciones y desarrollo", en Revista de Literatura, 2011, vol. 73., núm. 145, pp. 111-30.

${ }^{5}$ Vicente Quirarte Castañeda (ed.), "Estudio preliminar", en Republicanos en otro imperio. Viajeros mexicanos a Nueva York (1830-1895), 2009, México, UNAM, Programa Editorial de la Coordinación de Humanidades, p. 21.

${ }^{6}$ Citado por Felipe Texidor, Viajeros Mexicanos (Siglos XIXY XX), 1939, México, Ediciones Letras de México, p. 4. 
ricanos por tierras mexicanas pone de relieve las afirmaciones de Altamirano y refleja las condiciones económicas y sociales de un país que iba formándose erráticamente y a los tumbos.

Pero si para el siglo XIX esta condición modificaría en gran medida las perspectivas de los ciudadanos mexicanos, no borraría de un plumazo el carácter sedentario del hombre latinoamericano; el espíritu viajero, entendido el viaje "como aventura del alma, exploración de los sentidos", 7 seguiría siendo propiedad casi exclusiva del hombre proveniente del norte. Cabe entonces formularse las razones por las que el siglo XIX (heredero de la tradición viajera de los siglos XV y XVI) fue para Occidente un período de grandes exploraciones, de investigación cartográfica y científica. La cuestión debe pensarse en términos tanto culturales como económicos y políticos, pues durante el siglo XIX se fortaleció el concepto de nacionalismo y se reconfiguró el imperialismo occidental bajo el amparo de países como el Reino Unido, Francia y los Estados Unidos; todo esto ayudó, por supuesto, a fortalecer y resignificar la imagen del viajero de Occidente por tierras extranjeras, cuyo linaje ya contaba "con las categorías más diversas y sorprendentes: piratas y cartógrafos, científicos y desterrados, utopistas y comerciantes, artistas y desesperados"8 que vieron en las nuevas condiciones que ofrecía la modernidad una oportunidad para ejercer su arte, ampliar sus conocimientos, enriquecerse con el comercio, explotar la mano de obra indígena o exportar los cuantiosos recursos naturales de la tierra visitada.

El presente escrito, por tanto, centrará su atención en la vida y la obra de uno de esos hombres que cambiaron los rumbos de esta concepción sobre el carácter sedentario de los mexicanos: su nombre fue Francisco Bulnes (1847-1924) y su gesta radica en ser miembro de la primera expedición científica mexicana en circunnavegar la Tierra a finales del siglo XIX. La investigación también pondrá atención en la forma como Bulnes entiende el conocimiento del otro bajo los conceptos del progreso y la civilización forjados por el saber occidental. En este sentido, será importante destacar cómo se fraguó el conocimiento del otro por medio del dualismo civilización/barbarie.

${ }^{7}$ Quirarte, op. cit., p. 56.

${ }^{8}$ Ibid., p. 20. 


\section{Once mil leguas}

La noche del 18 de septiembre de 1874, los astrónomos Francisco Díaz Covarrubias y Francisco Jiménez, el topógrafo Manuel Fernández Leal y el fotógrafo Agustín Barroso, en compañía del ingeniero Francisco Bulnes, partirían en una comisión asignada por el presidente de la república mexicana, Sebastián Lerdo de Tejada, para visitar Yokohama, en el imperio del Japón, y tomar notas y registros científicos del tránsito de Venus por el disco solar. El evento sería presidido por varias comisiones científicas provenientes de las grandes potencias occidentales ${ }^{9}$ y prometía poner a México en la vanguardia de la investigación científica, amén de que, con la presencia de la comisión, el gobierno de Lerdo de Tejada mostraría a las naciones extranjeras su voluntad de llevar al país hacia la modernidad y el desarrollo económico-científico que caracterizaría al siglo XIX, que se instituía mediante los dogmas de las ideas liberales.

Bulnes señala en su texto, además, que el presidente Lerdo "anticipándose a satisfacer una de esas necesidades que la sociedad inspira y que el Estado realiza, nombró la comisión en la que tuve la honra de figurar con el carácter mixto de cronista y calculador" (SHN, p. 13), es decir, anticipándose a la necesidad de una nación que no sólo entendía el viaje emprendido hacia el oriente como un evento de naturaleza puramente científica sino, también, como un suceso cuyo impulso poseía claras connotaciones políticas, ${ }^{10}$ aunque para algunos, sin duda alguna, sería más una extravagancia o capricho del gobierno mexicano que un evento verdaderamente político o con funciones de investigación científica.

Pero esa extravagancia debe tomarse en su justa medida. En el siglo XIX tanto Francia como Inglaterra trasmitían un fuerte imagina-

\footnotetext{
${ }^{9}$ Sobre las diversas comisiones, Bulnes señala la presencia científica de naciones como Rusia, Estados Unidos, Inglaterra, Francia y Alemania, cuyas bases de observación se establecieron, además de en Japón, en Siberia, Egipto, China, Australia y Nueva Zelanda. La expedición mexicana, única en su género dadas las condiciones de pobreza y del reciente y turbulento pasado de la política interior y exterior del país, instaló sus dos observatorios en la provincia de Yokohama (véase SHN, p. 260).

${ }^{10}$ Cuauhtémoc Padilla, "Un ingeniero al otro lado del mundo", en Quirarte-Castañeda, op. cit., p. 234.
} 
rio que enalteció la perspectiva y la dimensión cultural que Occidente lograba a través de su proceso civilizador. La sociedad europea, a decir de Hegel, comenzó a ser concebida como el centro y el fin de la historia universal, constituida y cimentada bajo la quimera del progreso. Para los países latinoamericanos, los principios que las ideas liberales esgrimían formaban y "determinaban tanto la actuación política como la existencia cotidiana [de los pueblos que] adquirían los conceptos de nación, pertenencia, identidad". ${ }^{11}$ En su conjunto, la proclamación de las independencias latinoamericanas se había dado más en un plano emocional que político, comercial, social y cultural, la cosmovisión del sistema-mundo seguiría siendo más o menos la misma, pensada siempre en términos de inclusión/exclusión. ${ }^{12}$

En México, tras el fusilamiento de Maximiliano de Habsburgo, si bien se vivían todavía las consecuencias de la guerra, el desabastecimiento y el enorme gasto público, los programas de "desarrollo" impuestos por los gobiernos nacionales no dejaron de tener como referente e inspiración los modelos europeos y norteamericanos de la época. Comenzó, un período de relativa tranquilidad que se extendería hasta 1877. Durante esos diez años de paz y estabilidad, también las relaciones con los Estados Unidos parecieron entrar en aguas calmas, aunque el desorden y la anarquía seguían siendo tema recurrente en la agenda y el ejercicio de la política nacional. Más adelante, en el gobierno de Díaz, el país viviría una reestructuración política, económica y social que, a juicio de Martín Quirarte, consolidó lo que sería

${ }^{11}$ Quirarte-Castañeda, op. cit., pp. 24-5.

${ }^{12}$ Santiago Castro-Gómez, "El problema de la 'invención del otro"”, en Saurabh Dube, Ishita Banerjee Dube y Walter D. Mignolo (coords.), Modernidades coloniales. Otros pasados, historias presentes, 2004, El Colegio de México, Centro de Estudios de Asia y África, p. 289. Además, el proceso de exclusión y negación de la exterioridad efectuada por el saber occidental, explica Enrique Dussel, confrontó "lo sin valor ante los valores modernos, ante los criterios de civilización con pretensión (claim) de universalidad que Europa impuso como evaluación en todos los niveles" ("Sistema-mundo y "transmodernidad", en Dube, op. cit., p. 218), cuyos principios rectores se extendieron durante todo el siglo XIX sobre las culturas "periféricas" con una velocidad sorprendente "ya que los propios negados - dada su inferioridad industrial evidente- se ocuparon de aplaudir por medio de sus élites neocoloniales (educadas ahora en Europa y después en Estados Unidos), esa ideología eurocéntrica sin oponente crítico hasta hace muy poco", ibid., p. 218. 
"la administración más brillante del siglo XIX". ${ }^{13}$ Se impulsó la construcción del tendido férreo; se persiguió y se castigó a los contrabandistas, imponiendo la autoridad del Estado; se fortalecieron las industrias más importantes del país (como la petrolera y la minera) y se consolidó la banca. ${ }^{14}$ Estas circunstancias ayudaron al crecimiento del comercio exterior, que avanzó considerablemente en la escena económica internacional con miras al desarrollo tecnológico e industrial.

Bajo el telón de este confuso aunque también a veces prometedor escenario, se forjó el ingeniero Francisco Bulnes, hombre que según José Ricardo Chaves, pasará a la historia “cómo un desterrado intelectual porfirista, en especial por su labor en el campo histórico". ${ }^{15}$ En efecto, desde su perspectiva crítica sobre la historia nacional, desde su posición política en el senado y el congreso y, por su puesto, a través de su quehacer periodístico, Bulnes destacará en la historia de nuestras letras por su carácter "bélico", alguien que con su retórica "lograba unir en su contra a tirios y troyanos: los conservadores se lanzaban contra él por librepensador y anticlerical, y los liberales de su tiempo lo criticaban por escéptico y desencantado". ${ }^{16}$

Pero ese carácter combativo lo forjaría Bulnes durante su lento pero firme paso por la política y la historia mexicana, carácter que queda reflejado en obras como: El porvenir de las naciones latinoamericanas ante las recientes conquistas de Europa y Norteamérica. Estructura y evolución de un continente, de 1899; El verdadero Juárez y la verdad sobre la intervención y el imperio, de 1904; Las grandes mentiras de nuestra historia: la Nación y el Ejército en las guerras extranjeras, también de 1904; Juárez y las revoluciones de Ayutla y de Reforma, de 1906; o El verdadero Díaz y la Revolución, de 1920.

${ }^{13}$ Martín Quirarte, Visión panorámica de la historia de México, 1976, México, Librería Porrúa, novena edición, p. 227.

${ }^{14}$ Ibid., p. 246.

${ }^{15}$ José Ricardo Chaves, "Estudio preliminar”, en Bulnes, op. cit., p. 7. Librepensador, positivista, como funcionario del régimen porfirista logró ser elegido diputado y senador de la república, "si bien nunca llegó a los más altos niveles por suspicacias del propio don Porfirio, quien nunca llegó a confiar del todo en él. Quizás intuía que esa veta escéptica y punzante que tanta fama le había dado a don Pancho Bulnes pudiera terminar volviéndose en contra suya" (ibidem).

${ }^{16}$ Ibid., p. viii. 
No obstante la gran labor que como crítico de la historia nacional se le reconoce a Francisco Bulnes, en el ámbito de las letras debemos destacar la publicación de su primer texto, aparecido casi 50 años antes de la publicación póstuma de su última obra (Los problemas de México, de 1926): Sobre el hemisferio norte. Once mil leguas. Impresiones de viaje a Cuba, los Estados Unidos, el Japón, China, Conchinchina, Egipto y Europa, impreso en 1875 por la Imprenta de la Revista Universal, escrito, dice la portada de la edición original, por el "Historiógrafo de la Comisión Mexicana enviada al Japón por el Supremo Gobierno para observar el tránsito de Venus por el disco del Sol”.

Como historiógrafo de la comisión, Bulnes dedicará su tiempo a planear la construcción de un testimonio que dé cuenta de ese viaje alrededor del mundo, que inicia en el puerto de Veracruz y que lo llevará por mar a la isla de Cuba y a los Estados Unidos, de donde cruzará en tren desde la costa Este, en Nueva York (ciudad que aparecerá a los ojos del autor como la metrópoli del nuevo siglo), hasta la costa Oeste, en San Francisco, donde abordará el Vasco de Gama para emprender el viaje por las aguas del Pacífico californiano hasta las costas del Japón. Su recorrido asiático incluirá China (Hong Kong), Conchinchina, Saigón, Singapur y Ceilán (ahora Sri Lanka), países cuya vida política, estructura social y régimen legal despertarán el interés de Bulnes y lo impulsarán a esbozar los contornos de muros y ciudades tan antiguas como desconocidas para la cultura y el hombre mexicano. El viaje concluirá con el recorrido por Egipto, el canal de Suez, Nápoles, Roma y París, lugares que si bien despertarán el interés del narrador/viajero, no merecerán la atención que el lejano Oriente estimulará en la imaginación de Bulnes, ese continente donde "la opresión, la tiranía, el despotismo y todos los azotes de las monarquías obran sobre la población indígena" (SHN, pp. 208-9). Será la mirada de Bulnes una muestra de la influencia que el devenir de la ciencia positivista producirá en la política y la literatura mexicana, "no sin cierto dejo de ironía". ${ }^{17}$

Concretamente, el papel más importante que desempeñará la obra de Bulnes se encontrará en las descripciones que el autor realiza

\footnotetext{
${ }^{17}$ Padilla, op. cit., p. 234.
} 
sobre los Estados Unidos, donde encuentra el inicio de la modernidad que regirá al mundo durante la siguiente centuria y donde nacerá la idea de los "bárbaros modernos", que se extendería durante todo el siglo XX; será en las grandes metrópolis norteamericanas donde se forjará la figura del joven viajero convertido en crítico y escritor que, atento a la historia universal, creerá comprender y entrever el destino de las grandes civilizaciones occidentales: ${ }^{18}$

Cuando se miran atentamente las grandes obras que ilustran este pueblo, cuando se piensa en los prodigios que fascinan a todas las inteligencias, cuando se mide la fuerza que reside en este vigor incansable y la meditación que engendra tanta invención espontánea, se recuerda el que las civilizaciones pasadas no han florecido sino para secarse, no han aumentado sino para atraer la hiedra, esa poética fidelidad que surge del desastre. Se pregunta uno entonces si el coloso se desarticulará (SHN, pp. 88-9).

\section{El Tour du Monde}

La tradición francesa del Grand Tour o el Tour du Monde ${ }^{19}$ fue herencia de los viajes pedagógicos del siglo XVII y dio vida a un género literario de "reconocido prestigio entre los intelectuales ilustrados": el relato de viaje. ${ }^{20}$ Durante el siglo XIX, y gracias a las independencias de las colonias españolas, científicos, artistas, arqueólogos y coleccionistas incursionarían por las aguas del Atlántico para arribar al territorio

${ }^{18}$ El siglo XIX fue muy consciente de que mediante el fortalecimiento de la economía de libre mercado, del empuje de la ciencia y la tecnología, y de la exaltación de las ideas liberales, Occidente había creado pobreza infinita en los barrios periféricos de las grandes ciudades, concentrando el capital en manos inescrupulosas además de haber extendido la miseria y el exterminio a las colonias europeas de ultramar: "El horror del tráfico humano [expresaría Bulnes] lo absorbe la costa de África y lo castiga el crucero inglés" (SHN, p. 27).

${ }^{19}$ Ver Miguel Ángel Fernández, El coleccionismo en México, 2000, Monterrey, Museo del Vidrio; Luis Alburquerque García, "Algunas notas sobre la consolidación de los relatos de viaje como género literario”, en Ignacio Arellano, Víctor García y Carmen Saralegui (eds.), Ars bene docendi: Homenaje al profesor Kurt Spang, 2009, Navarra, Ediciones Universidad de Navarra.

${ }^{20}$ Alburqueque, 2009, op. cit., 29. 
americano y recorrer su vasta geografía; ${ }^{21}$ desde el desierto de Chihuahua hasta las montañas patagónicas, el hombre europeo inició un éxodo, también hoy conocido como viaje cultural, ${ }^{22}$ que le sirvió para dar forma a "su misión civilizadora", lo incitó a incrementar su conocimiento del otro y lo ayudó a apuntalar el nuevo rostro de materias como la antropología, la arqueología, la biología, la física, la botánica, la ingeniería o la medicina. Gracias también al viaje cultural surgió el estudio de las ciencias sociales, con las cuales Occidente resignificaría y reorientaría las miras de su proceso "civilizador", iniciado en el siglo XVI.

Imaginario bajo el cual Europa instituyó y fundó el concepto binario básico que sostuvo y fundamentó la modernidad: la civilización versus la barbarie. ${ }^{23}$ Debe destacarse que el papel de las ciencias sociales también sería imprescindible para Occidente en el sentido de que, por medio de ellas, el Estado moderno logró crear una identidad cultural y fijar metas a corto y largo plazo. "No sólo la reestructuración de la economía de acuerdo con las nuevas exigencias del capitalismo internacional, sino también la redefinición de la legitimidad política [que demandaba] representación científicamente avalada sobre el modo en que 'funcionaba' la realidad social". ${ }^{24}$

${ }^{21}$ Además, como advierte Mirella Marotta, un autor como Jean-Jaques Rosseau "ponía los viajes como fuente de conocimiento y de madurez intelectual, al igual que habían hecho Descartes y una gran cantidad de escritores y pensadores de la época, para los cuales la formación de cualquier muchacho de familia acomodada pasaba inexorablemente por una etapa de viaje por los lugares clásicos de la cultura europea. Pero, para quienes no tenían los medios o la edad necesarios para llevar a cabo esta aventura, la adquisición de conocimientos podía obtenerse igualmente a través de la lectura de los libros que otros viajeros habían escrito" ("El viaje como diálogo con el lector: la experiencia epistolar", en Eugenia Popeanga y Barbara Fraticelli (eds.), Las aventuras de viajar y sus escrituras, Revista de Filología Románica, Anejos, Serie de Monografías IV, 2006.

${ }^{22}$ Ver Javier del Prado Biezma, "Viajes con viático y sin viático", en Popeanga, op. cit.

${ }^{23}$ Ver Edgardo Lander, "Eurocentrismo, saberes modernos y naturalización del orden global del capital", en Dube, op. cit., p. 260.

${ }^{24}$ Castro-Gómez, op. cit., p. 288. Además, continúa explicando Castro-Gómez "Las taxonomías elaboradas por las ciencias sociales no se limitaban, entones, a la elaboración de un sistema abstracto de reglas llamado 'ciencia' [...], sino que tenían consecuencias prácticas en la medida en que eran capaces de legitimar las políticas regulativas del Estado. La matriz práctica que dará origen al nacimiento de las ciencias sociales es la necesidad de 'ajustar' la vida de los hombres al aparato de producción. Todas las políticas y las instituciones estatales [...] 
Durante el siglo XIX la voz del autor, dentro de los relatos de viaje, cobró fuerza y se convirtió en una instancia indispensable ${ }^{25} \mathrm{a}$ ello se agregó la búsqueda de la otredad y el conocimiento del otro. Situado en el conocimiento del otro, el viajero pudo desplegar una extensa red conceptual para comprender los signos de la diversidad mediante descripciones que jamás pudieron ser neutrales ${ }^{26}$ (pues siempre estuvieron regidas por la dicotomía civilización/barbarie), sino que aparecieron en diversos grados de valoración y evaluación etnicocultural, cuyos juicios quedan de manifiesto en la obra de Bulnes cuando describe a los habitantes de la China como "salvajes cultivadores de arroz" (SHN, p. 199). Bulnes acusa a los pobladores chinos de perversos por negarse a aceptar el progreso occidental e ir en contra de los designios de quienes "se han obligado a civilizarlo[s]" (ibidem); considera que gran parte de los asiáticos, principalmente en China, parecen "vivir en cierto medio bestial, fuera de toda idea religiosa, de toda noción de derecho y en las cavernas de una moral que a veces reconoce el delito" (SHN, p. 209). ${ }^{27}$ El comentario cobra mayor relevancia (y se torna por supuesto irónico) si consideramos que quien lo emite es un hombre latinoamericano que, si bien pertenece a las elites criollas mexicanas, para la visión occidental es originario de un pueblo que queda fuera de la civilización y se inscribe en el ámbito de la barbarie.

Pero este contacto, aunque se haya dado en términos de confrontación, tuvo un alcance cognoscitivo al tiempo que ontológico, porque el viajero, al preguntarse quiénes son los otros, forzosamente tuvo que indagar en las perspectivas de su propia identidad. Acto de aprehensión de la alteridad que forjó el deseo y la necesidad de la representación del

vendrán definidas por el imperativo jurídico de la 'modernización', es decir, por la necesidad de disciplinar las pasiones y orientarlas hacia el beneficio de la colectividad por medio del trabajo" p. 288.

${ }^{25}$ Alburquerque, 2009, op. cit.

${ }^{26}$ Marco Urdapilleta, op. cit.

${ }^{27} \mathrm{Si}$ bien las impresiones que realiza Bulnes sobre las culturas y las sociedades del lejano Oriente son exhaustivas y están bien documentadas, en lo general no difieren mucho de las observaciones plasmadas por otros autores de la época sobre el continente, de ahí que se haya decidido no profundizar en las descripciones asiáticas y centrar toda la atención en el dibujo que el autor esboza sobre los Estados Unidos, donde radica la verdadera originalidad de la crítica que Bulnes construye durante su recorrido por el país del norte. 
otro, ${ }^{28}$ evento que trazó la ruta narrativa del relato de viaje (y del viaje cultural o el Tour du Monde) durante todo el siglo XIX.

Si durante el siglo XIX el viaje representó para las élites europeas la iniciación cultural y civilizatoria, para el hombre latinoamericano, además de constituir un proceso de formación inexcusable, el viaje llegaría a simbolizar la apertura espiritual que le permitía proyectarse allende sus fronteras y compararse con las culturas de otras latitudes. En el relato de viaje, la narración abre paso a la descripción, y ésta, invariablemente, da pie a los actos de observar, reflexionar y expresar, ${ }^{29}$ y a los de contrastar, confrontar y conceptualizar. En este sentido, el tratamiento de la ideología en los relatos de viaje se torna fundamental, pues su eje girará en torno a la estructuración de una tipología sobre la otredad que en el siglo XIX tendrá como marco legal ${ }^{30}$ para explicar las relaciones con la alteridad cultural, además de la dicotomía civilización versus barbarie, el dualismo cultura versus naturaleza, que en el texto de Bulnes cobra singular relevancia: "Sin la civilización el hombre es el esclavo más servil de la naturaleza" (SHN, p. 25).

Las oposiciones civilización/barbarie y cultura/naturaleza, tan propias del canon occidental y de la tradición cientificista del siglo XIX, forjaron en Bulnes, así como en tantos otros pensadores positivistas y liberales de la época, un deseo civilizatorio que orientó su quehacer científico, intelectual y literario:

Al conocer una de las primeras obras de nuestro siglo [dice Bulnes sobre los Estados Unidos], la imaginación, templándose en el asombro, recoge por mucho tiempo las imaginaciones inolvidables que presenta la ciencia después de haber violado a la naturaleza, y se experimentan movimientos indefinibles de gratitud hacia los que han podido desempeñar el trabajo de los gigantes. Estas montañas que cortaban el paso al progreso se han dejado vencer por pigmeos excitados por la ambición, y muestran sus entrañas ennegrecidas por la pólvora y destrozadas por la barreta (SHN, p. 84).

${ }^{28}$ Ibidem.

${ }^{29}$ Ver Sofía Carrizo Rueda, Poética del relato de viajes, 1997, Kassel, Reichenberger; Alburquerque, op. cit.

${ }^{30}$ Urdapilleta, op. cit. 
Resalta el carácter fuertemente positivista que la mirada de Bulnes desplegará para hablar de la ingeniería y la ciencia norteamericana, carácter que resulta afín al humanismo forjado durante el siglo XIX y que puso de relieve la necesidad del hombre occidental de crear un mundo regido por los principios básicos de la ciencia y el conocimiento; ${ }^{31}$ estos mismos principios fraguarían y harían posible la invención del otro, no sólo en los términos en los que una sociedad representa mentalmente a otra, sino también en los términos "saber/poder a partir de los cuales esas representaciones son construidas", ${ }^{32}$ conocimiento que se fue originando a partir del siglo XVI bajo "una lógica binaria que reprimía las diferencias". ${ }^{33}$

El ejemplo más impactante del proceso civilizatorio se desarrollaría en las regiones septentrionales de los Estados Unidos, donde comenzaba a crecer a un ritmo incontrolable el libre comercio, que ponía de relieve la fortaleza económica y comercial de ciudades como Nueva York, y mostraba al mundo "los logros y esplendores de la civilización material". ${ }^{34}$ Esto resulta de gran importancia para el estudio de la obra de Bulnes porque dentro de sus páginas, si bien la cultura europea despierta asombro y admiración, será la civilización que se desarrolla en el norte de América la que estimulará los comentarios más entusiastas.

Brazos más poderosos que los que se encargaron del trabajo de Cléops [sic] levantaron ciudades; el espíritu, separado de las discusiones religiosas, y aplicado constantemente a profanar los misterios del movimiento

${ }^{31}$ Castro-Gómez, op. cit., p. 286.

${ }^{32}$ Ibid., p. 288.

${ }^{33} \mathrm{Ibid}$., p. 285. Que también alimentó el imaginario de los intelectuales y de las élites criollas en América Latina bajo otros dualismos como: ciencia/mito, desarrollo/subdesarrollo, hombre/ mujer, de los que hablan Castro-Gómez, Lander y Dussel y que sostuvieron el quehacer de las ciencias sociales en Occidente.

${ }^{34}$ Quirarte-Castañeda, op. cit., p. 25. Francisco Bulnes agrega sobre la ciudad de Nueva York: "Antes de la era cristiana se hablaba de Memphis, de Cartago, de Persia; se hablaba también de Atenas; pero a este gran recuerdo, solo París puede responder. Se habló más tarde de Bizancio, de Génova y de Venecia: hoy se habla de Nueva York, indicando dónde han ido a anidar las águilas que paseaban en el espacio la vieja gloria del mundo, y que han huido de las tumbas de Italia, de las ruinas de Egipto y de la decadencia de España” (SHN, p. 43). 
y el secreto de las fuerzas vivas, absorbió a poco tiempo los conocimientos que tenía acumulado el viejo continente. La mecánica y la geometría condujeron a la sociedad, desacreditando al hombre sensible. Se le votó a Dios una constitución, y el sufragio universal ocupó el lugar de todas las locuras (SHN, p. 44).

Si bien a veces acude a la ironía y al escepticismo para describir el afán de progreso y el incipiente comercio que se desarrolla en el país vecino: ${ }^{35}$

Espero que dentro de algunos años no solo se recibirá el tabaco turco y el índigo de la India, sino que habrán establecido casas de comisión para importar pasiones y sentimientos del dominio exclusivo de los otros pueblos. Se emitirán acciones en el mercado sobre algún placer inventado en París, y se pedirá privilegio para introducir sonrisas japonesas que aumenten el arsenal del bello sexo (SHN, p. 45).

No puede pasarse por alto su profundo interés por describir a la nación cuyo avance económico era incontrolable y amenazaba con desplazar a las naciones europeas que, hasta entonces, dominaban el comercio mundial y dirigían los cauces del colonialismo. ${ }^{36}$ Bulnes concebiría a Nueva York como la representación de la nueva urbe occidental, la Ciudad Imperio, como sería llamada a finales del siglo XIX.

Al presente, ayudados por la configuración geográfica de su país y por casualidades favorables, explotadas con atrevimiento, energía y perseverancia, han convertido a Nueva York en el primer templo de la enormidad, religión dominante en los Estados Unidos. Desde los suburbios de la ciudad se presiente el Broadway, con sus lujosos almacenes, sus grandes hoteles, su legión de bancos y su infinidad de anuncios.

${ }^{35}$ Vemos ya en germen la desconfianza que producían para algunos círculos intelectuales la propagación de las ideas liberales y la economía de libre mercado que proliferaba y había enriquecido a las naciones más desarrolladas; esta desconfianza se dará principalmente en los círculos intelectuales que se habían acogido a las ideas del pesimismo histórico y cultural (ver Arthur Herman, La idea de decadencia en la historia occidental, 1997, Barcelona, Andrés Bello, trad. Carlos Gardini).

36 "En América las últimas piedras del edificio serán escogidas entre las ruinas de Europa" (SHN, p. 89). 
En este océano humano perpetuamente enfurecido, se desarrollan lentas ondulaciones que se rompen en construcciones colosales o se deshacen en las avenidas (SHN, p. 45).

Bulnes vería en ese "coloso" los signos más evidentes del progreso, "cuya prosperidad es casi secular" (SHN, p. 41), y los rasgos de la nueva barbarie que los intelectuales creían percibir en las sociedades tecnológicas e industriales. El autor se asomará así a una concepción que sobre la idea del progreso y la civilización se había ido forjando en los espacios culturales y académicos del siglo XIX y que, a partir de las ideas nietzscheanas, cobrarían un fuerte impulso durante las siguientes décadas.

La música les atrae como el Niágara, por el ruido. Necesitan un torrente de notas como en el concierto de Boston, donde se dispararon cien cañonazos para marcar un calderón [...]. Si se pudiesen proporcionar la gran trompeta que debe agitar las cenizas de Josafat, olvidarían el violín y el piano, y ayudados de sus locomotoras, despertarían para siempre las melodías del genio italiano.

Para ellos, el gusto se encuentra en la cantidad de efecto, y creen gozar cuando alcanzan un estado apoplético de conciencia, en medio de una de esas apoteosis del estruendo (SHN, p. 46).

Como muchos otros intelectuales de su época, Francisco Bulnes fue testigo del ascenso estadounidense en la política y la economía internacional, donde el "comercio está considerado como el agente más enérgico para perfeccionar la vida" (SHN, p. 44). Durante su paso por los Estados Unidos, comprendería con claridad el papel que jugaban nuestros vecinos del norte en la nueva configuración del orbe, un mundo moderno donde la tecnología, la ciencia y el progreso parecían deshumanizar al individuo civilizado, cuyos "estómagos funcionan como las máquinas de vapor de su poderosa industria” (SHN, p. 46), es decir, como una auténtica y colosal maquinaria de consumo, "epopeya de la piedra, del fierro y del papel moneda, tan bien sentida por los dioses de las finanzas" (SHN, p. 46). 
No obstante, las observaciones de Bulnes no serán las de un simple aficionado o un detractor de la nación "que más ama la civilización" (SHN, p. 46). Durante el siglo XIX, el esplendor del desarrollo estuvo eclipsado por la sensación de decadencia e incertidumbre. Autores como Henry Brooks Adams, herederos de la tradición pesimista europea, veían en el progreso norteamericano los signos más alarmantes de la profundidad y el daño social que la inmigración, la industrialización y la política democrática de masas estaba generando en las sociedades desarrolladas. Pero mientras los europeos se refugiaban en un pasado premoderno glorioso y en los "logros culturales de épocas anteriores, tales como el mundo antiguo y la Edad Media", ${ }^{37}$ para los norteamericanos no existía esa opción cultural e histórica: "No hay allí responsabilidades por el pasado, puesto que no hay tradición. La historia pide sólo a los salvajes sus guerras y un día de sus costumbres" (SHN, p. 43).

Porque la riqueza material creaba desigualdades abismales que, creían algunos, requerían cambios radicales en los sistemas y las políticas públicas del gobierno para evitar el colapso social. La corrupción, la degeneración, la economía de libre mercado y el caos político enquistado en el clientelismo representaban para muchos el rostro más vil de la codicia que se usaba para medir al ser humano en "términos mecánicos y no espirituales". ${ }^{38}$ La enorme acumulación del capital en unas cuantas manos y el creciente materialismo en la vida de las sociedades desarrolladas, que encontraba su cúspide en Norteamérica, principalmente en ciudades como Nueva York, Filadelfia o Chicago, auguraban una inminente degeneración y degradación del espíritu del hombre moderno: 39

En 1870 [explica Arthur Herman] las granjas americanas aún producían más riqueza que las fábricas; hacia el 1900 la producción industrial era tres veces superior a la agrícola. A diez años de la Guerra Civil, las principales personalidades e instituciones de la era industrial moderna ya estaban en su sitio. El ferrocarril transcontinental se completó en 1896, y un

${ }^{37}$ Herman, op. cit., p. 158.

${ }^{38}$ Ibid., p. 170.

${ }^{39}$ Ibid., p. 179. 
año después John D. Rockefeller creó la Standard Oil Company en los yacimientos petrolíferos del oeste de Pennsylvania. Al año siguiente J. Pierpont Morgan fundó Drexel, Morgan \& Company y se convirtió en el banquero más poderoso del mundo. En 1876 Andrew Carnegie fundó United Status Steel, prototipo de las grandes empresas industriales, Thomas A. Edison inauguró su laboratorio de Menlo Park y Alexander Graham Bell presentó su primer teléfono funcional en la Exposición del Centro de Filadelfia. ${ }^{40}$

Inmerso en un panorama que intuía el inminente colapso del poderoso Estado moderno, corrupto e ineficiente, Bulnes, como hombre de ciencia, no pudo dejar de preguntarse sobre el destino que también la aguardaba a nuestro país y en general a las naciones latinoamericanas, a las que pronosticaba un futuro incierto. En medio del esplendor de la prosperidad de la civilización material, Bulnes, como muchos otros autores, se acogió a una tradición pesimista que veía los triunfos del liberalismo europeo con cautela; prueba de ello es su vasta bibliografía, que toca temas como el destino político y social del continente, México en particular, y su relación con las grandes naciones occidentales. Pesimismo que la valió el rechazo de los círculos revolucionarios y progresistas, pero que también lo alejaban de los bandos reaccionarios de su época y que lo ayudaron a construir un carácter único que, como lo califica José Ricardo Chaves, lo convertían en un "escéptico y libre pensador": ${ }^{41}$

Se recorren estas llanuras como las de otro planeta sin poder tomar al recuerdo nada de un pasado lejano. La imaginación interroga a esos

${ }^{40}$ Ibid., p. 171. "La exposición [continúa] era un potente símbolo del predominio de la máquina en el nuevo paisaje americano. Durante ese mismo período la población del país se duplicó [...]. Estas transformaciones eran un doble golpe para una élite social e intelectual que ya había sido sorprendida por la política democrática masiva. El poder de las grandes empresas y monopolios parecía amenaza tan decisiva para los valores tradicionales como para los aparatos partidarios. En el año siguiente a la exposición del Centro estallaron varias huelgas ferroviarias y en 1873, 1893 y 1906 hubo grandes pánicos financieros. La concentración industrial, la incertidumbre económica y la inquietud laboral se convirtieron en hitos de la Edad del Oropel [...]. Para el joven Albert Jay Nock, que crecía en Nueva York, el país parecía estar en las garras de lo que él llamaba 'economismo', el cual 'interpreta toda la vida humana conforme con la producción, la adquisición y la distribución de la riqueza'. El lema era 'aprópiate' que era la 'moral del saqueador', ibid., pp. 171-2.

${ }^{41}$ Chaves, op. cit., p. IX. 
valles fértiles, a esas montañas que elevan el horizonte, a ese río que refleja el paso del tren, de donde viene esa muerte perfecta que impide responda siquiera una piedra a la ansiedad científica del viajero, instigado por esa necesidad que experimenta el hombre de entrar en comunión con las cosas, de remontarse a su origen, de explicarse sus trasformaciones y de pedirle a una historia que ensanche aparentemente los límites de la vida humana (SHN, p. 75).

Gracias a su viaje alrededor del mundo, Bulnes, como tantos otros viajeros de su tiempo, logró crear una cartografía etnográfica de las culturas visitadas que, aunque presidida por una visión positivista y civilizatoria, invitó al autor a adentrarse en la indagación y en la búsqueda del otro, lo que infaliblemente lo llevó años más tarde al reconocimiento y al estudio de lo propio. De ahí la importancia de retomar este tipo de estudios, reflejo y testimonio de nuestro pasado; de ahí, también, la importancia de llevar a cabo un proceso exhaustivo de reedición y rescate de los crónicas de los viajeros mexicanos del siglo XIX, pues al rescatar esos testimonios conservamos la fisonomía inquebrantable de nuestra identidad y de nuestra historia. 